\title{
Crystal Structure of 4-Acetoxy-3-[1-(4-nitrophenyl)-3-oxobutyl]-2H-1- benzopyran-2-one
}

\author{
Ilia MAnOLov ${ }^{* \dagger}$ and Caecilia MAIChLE-MoesSMER** \\ *Department of Organic Chemistry, Faculty of Pharmacy, Medical University, 2, Dunav St., 1000 Sofia, \\ Bulgaria \\ **Institute of Inorganic Chemistry, Auf der Morgenstelle 18, 72076 Tuebingen, Germany
}

\begin{abstract}
The title compound, 4-acetoxy-3-[1-(4-nitrophenyl)-3-oxobutyl]-2H-1-benzopyran-2-one, $\mathrm{C}_{21} \mathrm{H}_{17} \mathrm{NO}_{7}$, crystallized in the monoclinic system, space group $P 2_{1} / a$, with cell constants $a=9.5505(13) \AA, b=11.9546(11) \AA, c=16.336(2) \AA, \beta=$ 97.497(12),$V=1849.2(4) \AA^{3}$ and $Z=4$. The compound crystallized in the open-chain keto form and had only one asymmetric center at $\mathrm{C} 15$.
\end{abstract}

(Received April 6, 2007; Accepted July 23, 2007; Published on web September 6, 2007)

4-Hydroxycoumarin derivatives are of interest because of their physiological, photodynamic, anticoagulant, spasmolytic, bacteriostatic, and rodenticidal activities. Some coumarin derivatives are known for their antibiotic and antifungal activities. They are also used as analytical reagents. The most widely used antithrombotic in USA and Canada is racemic sodium warfarin. It is possible to obtain compounds with good biological activity, but with lower toxicity and fewer side effects, by chemical modifications of the warfarin structure.

The title compound, 4-acetoxy-3-[1-(4-nitrophenyl)-3oxobutyl]-2H-1-benzopyran-2-one, was synthesized from 4'nitrobenzylideneacetone and 4-hydroxycoumarin, and the next step was treating 4-hydroxy-3-[1-(4-nitrophenyl)-3-oxobutyl]2H-1-benzopyran-2-one with acetic acid anhydride.

The structure of the synthesized compound was proven by IR, ${ }^{1} \mathrm{H}-\mathrm{NMR}$ and mass-spectral analyses. Acute toxicity studies of the compound were performed on mice by oral and intraperitoneal administration. The investigated compound showed a lower acute toxicity and a higher anticoagulant activity than Warfarin.

The crystal structure of the compound was determined using the single-crystal X-ray diffraction method. Data collection of this compound was done at $173(2) \mathrm{K}$ using graphite monochromator Mo- $K_{\alpha}(\lambda=0.71073 \AA)$ radiation on an ENRAF NONIUS four-circle difractometer. Complete data<smiles>CC(=O)CC(c1ccc([N+](=O)[O-])cc1)c1c(OC(C)=O)c2ccccc2oc1=O</smiles>

Fig. 1 Chemical structure of 4-acetoxy-3-[1-(4-nitrophenyl)-3oxobutyl]-2H-1-benzopyran-2-one.

$\dagger$ To whom correspondence should be addressed. E-mail: imanolov@gmx.net collection parameters and details of the structure solution and refinement are given in Table 1. Further details on the crystal structure investigation are available free of charge at www. ccdc.ac.uk/conts/retrieving.html or deposit@ccdc.cam.ac.uk.

The unit cell was determined and refined using the CAD4EXPRESS program. The space group was determined using the check-hkl and was performed with the PLATON/ABS PSI program. ${ }^{2}$ The structure was solved with direct methods by

Table 1 Crystal and experimental data

\begin{tabular}{ll}
\hline Empirical formula & $\mathrm{C}_{21} \mathrm{H}_{17} \mathrm{NO}_{7}$ \\
Formula weight & 395.36 \\
Temperature & $173(2) \mathrm{K}$ \\
Wavelength & $0.71073 \AA$ Ao $K_{\alpha}$ \\
Crystal system/Space group & Monoclinic, $P 2_{1} / a$ \\
Unit cell dimensions & $a=9.5505(13) \AA ;$ \\
& $b=11.9546(11) \AA ; \beta=97.497(12)^{\circ}$ \\
& $c=16.336(2) \AA ;$ \\
Volume & $1849.2(4) \AA^{3}$ \\
$Z$ & 4 \\
Density (calculated) & $1.420 \mathrm{Mg} / \mathrm{m}^{3}$ \\
Absorption coefficient & $0.108 \mathrm{~mm}{ }^{-1}$ \\
$F(000)$ & 824 \\
Crystal size & $0.65 \times 0.15 \times 0.10 \mathrm{~mm}$ \\
$\theta$ range for data collection $\left[{ }^{\circ}\right]$ & 3.13 to $26.96 \mathrm{deg}$. \\
Index ranges & $-12<=h<=10,-15<=k<=15$, \\
& $-20<=1<=20$ \\
Reflections collected & 26333 \\
Indipendent reflections & $3956\left[R_{\text {(int) }}=0.0883\right]$ \\
Reflections observed & 2815 \\
Criterion for observation & $>2 \sigma(I)$ \\
Absorption correction & None \\
Measurement method & Phi-Scans \\
Refinement method & Full-matrix least-squares on $F^{2}$ \\
Data/restrains/parameters & $3956 / 0 / 330$ \\
Final $R$ indices $[I>2 \sigma(I)]$ & $R 1=0.0644, w R 2=0.1252$ \\
Goodness-of-fit on $F^{2}$ & 1.130 \\
Final $R$ indices (all) $R 1 / w R 2$ & $0.0993 / 0.1388$ \\
Largest diff. peak and hole & 0.221 and -0.177 e. $\AA^{-3}$ \\
CCDC & 652259 \\
&
\end{tabular}




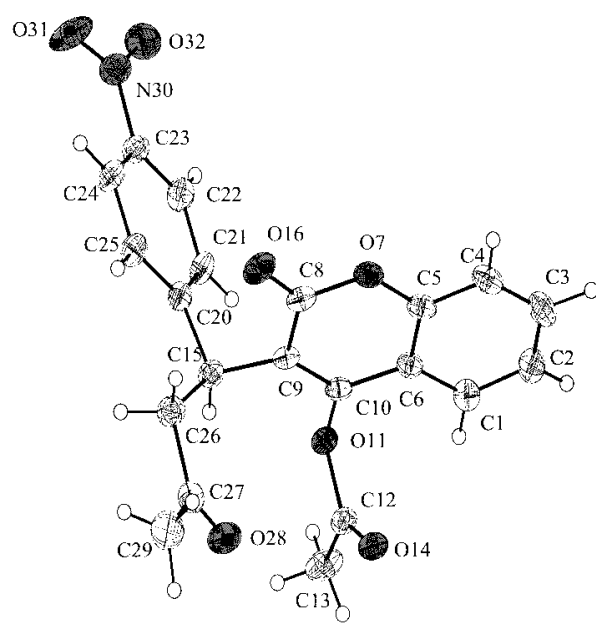

Fig. 2 DIAMOND drawing (50\% probability level).

SHELXS97 and refined by SHELXL97. ${ }^{3}$ The structure was refined by least-square methods based on $F^{2}$. All non-hydrogen atoms were fully refined in the calculated position. The hydrogen atoms were taken from the electron density map and refined isotropically. Plots of the molecular structure were made using the DIAMOND program (CRYSTAL IMPACT GbR, Bonn, Germany). ${ }^{4}$

Colorless prismatic crystals, suitable for X-ray diffraction analysis, were grown by slow evaporation of an ethyl acetate solution. Crystallographic data for the investigated compound are listed in Table 1. The solid-state structure is shown in Fig. 2.

The title compound, 4-acetoxy-3-[1-(4-nitrophenyl)-3oxobutyl]-2H-1-benzopyran-2-one, is a structural analogue of Warfarin. X-ray crystal structure analyses showed that this compound crystallized in the monoclinic system, space group $P 2_{1} / a$. An examination of the bond lengths revealed that the atoms retained the character expected for an open-side chain (keto) compound. The O11-C10 bond length of 1.389(3) $\AA$ is close to that of the phenolic $\mathrm{C}-\mathrm{O}$ bond. Moreover, the bond lengths between C26-C27 and between C27-C29 are 1.515(4) and $1.505(4) \AA$, respectively, close to the expected values for $\mathrm{C}-\mathrm{C}$ bonds adjacent to carbonyl groups. In the structure of the investigated compound there is no bond between $\mathrm{C} 27$ and $\mathrm{O} 11$. Within the coumarin system, the length of the double bond C9-C10, 1.347(3) $\AA$ is suitable for a C=C bond conjugated to a carbonyl, and the adjacent C8-C9 bond of 1.468(3) $\AA$ is slightly shorter than expected because of resonance. Two near disposed planarities of the coumarin ring system and the aromatic nucleus formed an angle between C9-C15-C20 of 107.3(2) . The compound crystallized in the open-chain keto form and had only one asymmetric center at $\mathrm{C} 15$. No hemiketal ring was formed in the investigated compound.
Table 2 Atomic coordinates and equivalent isotropic displacement parameters $\left(\mathrm{A}^{2} \times 10^{3}\right)$. [ $[U(\mathrm{eq})$ is defined as one third of the trace of the orthogonalized $U \mathrm{ij}$ tensor)

\begin{tabular}{lrrrr}
\hline Atom & $x$ & $y$ & $z$ & $U(\mathrm{eq})$ \\
\hline C 1 & $0.2765(3)$ & $0.1478(2)$ & $0.4938(2)$ & $35(1)$ \\
C 2 & $0.3284(3)$ & $0.1747(2)$ & $0.4213(2)$ & $42(1)$ \\
C 3 & $0.4713(3)$ & $0.1704(2)$ & $0.4159(2)$ & $44(1)$ \\
C 4 & $0.5662(3)$ & $0.1405(2)$ & $0.4834(2)$ & $39(1)$ \\
C 5 & $0.5147(3)$ & $0.1180(2)$ & $0.5576(2)$ & $32(1)$ \\
C 6 & $0.3707(2)$ & $0.1198(2)$ & $0.5643(1)$ & $29(1)$ \\
O 7 & $0.6125(2)$ & $0.0918(1)$ & $0.6239(1)$ & $35(1)$ \\
C 8 & $0.5746(2)$ & $0.0637(2)$ & $0.6997(2)$ & $33(1)$ \\
C 9 & $0.4244(2)$ & $0.0689(2)$ & $0.7102(1)$ & $27(1)$ \\
C 10 & $0.3295(2)$ & $0.0945(2)$ & $0.6445(1)$ & $26(1)$ \\
O 11 & $0.1885(2)$ & $0.1073(1)$ & $0.6553(1)$ & $30(1)$ \\
C 12 & $0.0929(2)$ & $0.0286(2)$ & $0.6188(2)$ & $32(1)$ \\
C 13 & $-0.0513(3)$ & $0.0585(4)$ & $0.6378(2)$ & $55(1)$ \\
O 14 & $0.1261(2)$ & $-0.0468(2)$ & $0.5777(1)$ & $37(1)$ \\
C 15 & $0.3865(3)$ & $0.0554(2)$ & $0.7972(2)$ & $31(1)$ \\
O 16 & $0.6694(2)$ & $0.0383(2)$ & $0.7527(1)$ & $44(1)$ \\
C 20 & $0.4513(2)$ & $0.1542(2)$ & $0.8481(1)$ & $31(1)$ \\
C 21 & $0.3977(3)$ & $0.2611(2)$ & $0.8300(2)$ & $35(1)$ \\
C 22 & $0.4595(3)$ & $0.3548(2)$ & $0.8687(2)$ & $39(1)$ \\
C 23 & $0.5766(3)$ & $0.3394(2)$ & $0.9271(2)$ & $37(1)$ \\
C 24 & $0.6306(3)$ & $0.2354(2)$ & $0.9486(2)$ & $39(1)$ \\
C 25 & $0.5668(3)$ & $0.1425(2)$ & $0.9089(2)$ & $37(1)$ \\
C 26 & $0.4250(3)$ & $-0.0599(2)$ & $0.8353(2)$ & $39(1)$ \\
C 27 & $0.3341(3)$ & $-0.1548(2)$ & $0.7965(2)$ & $43(1)$ \\
O 28 & $0.2238(2)$ & $-0.1376(2)$ & $0.7523(1)$ & $57(1)$ \\
C 29 & $0.3881(5)$ & $-0.2714(3)$ & $0.8159(2)$ & $61(1)$ \\
N 30 & $0.6496(3)$ & $0.4382(2)$ & $0.9661(2)$ & $52(1)$ \\
O 31 & $0.7450(3)$ & $0.4219(2)$ & $1.0227(2)$ & $80(1)$ \\
O 32 & $0.6123(3)$ & $0.5313(2)$ & $0.9406(1)$ & $66(1)$ \\
\hline
\end{tabular}

Savell et al. ${ }^{5}$ established that the substance analogous of Sythrom crystallized in the triclinic system, space group $P 1$. It formed an intramolecular hemiketal and possessed two asymmetrical $\mathrm{C}$ atoms.

Obviously, the substitution of a hydrogen atom in the phenol hydroxyl group at C-4 of the coumarin fragment did not allow the formation of an intramolecular hemiketal.

\section{References}

1. I. Manolov and N. D. Danchev, Eur. J. Med. Chem., 1995, 30, 531 .

2. A. L. Spek, PLATON: General Crystallographic Tool; Utrecht University, The Netherlands, 1998.

3. G. M. Sheldrick, SHELXL97. Program for crystal structure refinement, University of Gottingen, Germany, 1997.

4. K. Brandenburg, DIAMOND (version 3.0), Crystal and Molecular Structure Visualization, Crystal Impact-K. Brandenburg \& H. Putz GbR, Bonn (Germany), 2004.

5. V. H. Savell, Jr., E. J. Valente, and D. S. Eggleston, Acta Cryst., 1989, C45, 1908. 